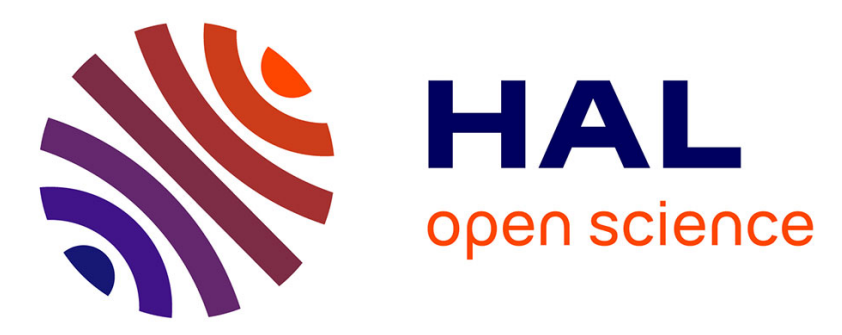

\title{
Drug launch timing and international reference pricing
}

Nicolas Houy, Izabela Jelovac

\section{To cite this version:}

Nicolas Houy, Izabela Jelovac. Drug launch timing and international reference pricing. 2013. halshs00782179

\section{HAL Id: halshs-00782179 \\ https://shs.hal.science/halshs-00782179}

Preprint submitted on 29 Jan 2013

HAL is a multi-disciplinary open access archive for the deposit and dissemination of scientific research documents, whether they are published or not. The documents may come from teaching and research institutions in France or abroad, or from public or private research centers.
L'archive ouverte pluridisciplinaire HAL, est destinée au dépôt et à la diffusion de documents scientifiques de niveau recherche, publiés ou non, émanant des établissements d'enseignement et de recherche français ou étrangers, des laboratoires publics ou privés. 
Drug launch timing and international reference pricing

Nicolas Houy, Izabela Jelovac

January 2013 


\section{GATE Groupe d'Analyse et de Théorie Économique Lyon-St Étienne}

93, chemin des Mouilles 69130 Ecully - France

Tel. +33(0)4 72866060

Fax $+33(0) 472866090$

6, rue Basse des Rives 42023 Saint-Etienne cedex 02 - France

Tel. +33 (0)4 77421960

Fax. +33 (0)4 77421950

Messagerie électronique / Email : gate@gate.cnrs.fr

Téléchargement / Download : http://www.gate.cnrs.fr - Publications / Working Papers 


\title{
Drug launch timing and international reference pricing
}

\author{
Nicolas HouY* Izabela JELOVAC ${ }^{\dagger}$
}

January 25, 2013

\begin{abstract}
This paper analyzes the timing decisions of pharmaceutical firms to launch a new drug in countries involved in international reference pricing. We show three important features of launch timing when all countries reference the prices in all other countries and in all previous periods of time. First, there is no withdrawal of drugs in any country and in any period of time. Second, there is no strict incentive to delay the launch of a drug in any country. Third, whenever the drug is sold in a country, it is also sold in all countries with larger willingness to pay. We then show that the three results do not hold when the countries only reference a subset of all countries. The first two results do not hold when the reference is on the last period prices only.

Key-Words: Drug launch timing, international reference pricing.

JEL Classification: I11, L65.
\end{abstract}

${ }^{*}$ University of Lyon, Lyon, F-69007, France; CNRS, GATE Lyon Saint-Etienne, Ecully, F-69130, France. E-mail: houy@gate.cnrs.fr.

${ }^{\dagger}$ University of Lyon, Lyon, F-69007, France; CNRS, GATE Lyon Saint-Etienne, Ecully, F-69130, France. E-mail: jelovac@gate.cnrs.fr. 


\section{Introduction}

When launching a new drug on the international market, pharmaceutical firms decide on two important strategic dimensions: the pricing and the timing of launches for all countries. The timing of launches partly depends on aspects that are out of the firms' control, such as the (supra-) national requirements of quality, safety and efficacy proofs and the length of time needed by the regulatory authorities to review the new product dossier. However, the timing of launches is also a best response of firms to some regulatory tools. In particular, international reference pricing (IRP) is generally held responsible for the sequential launching of new drugs. The many countries that use IRP impose a price cap that is based on the prices of the same product in other reference countries. This policy leads to an interdependence of prices between countries. Many authors recognize that this interdependence gives pharmaceutical firms an incentive to launch new drugs in high-price countries first and to delay launch or even not to launch new drugs in low-price countries. See [Danzon and Epstein, 2008], [Danzon et al., 2005], [Kyle, 2007], [Lanjouw, 2005], [Rankin, 2003], [Varol et al., 2012].

So far, no theoretical results exist on this issue. The paper by [Richter, 2008] provides a general game-theoretical framework to analyze the implications of international price interdependencies. This framework may prove useful for simulating the effects of IRP. However, it does not provide an optimal solution to the pricing and timing decision problem of firms because of its high complexity. Such theoretical results would be very important though both to guide empirical research on this issue and to inform health authorities about the possible consequences of regulatory tools such as international referencing. In particular, it is very important to distinguish between the two possible consequences of IRP, that is, either launches delays or absence of launch. The modalities of application of IRP can also vary. For instance, international referencing can be retroactive or not. [Rankin, 2003] noted 
that retroactive IRP might place further restrictions on pricing strategy, limiting some of the rationale that is used to support a sequential entry strategy for a global launch. Furthermore, the basket of reference countries can be complete in the sense that all countries reference each other, or not. It is therefore important to check whether different IRP modalities have different implications.

Several authors have empirically demonstrated and agreed on the link between IRP and the timing of launches. [Danzon and Epstein, 2008] find significant evidence that regulatory referencing by high-price countries to lower-price countries within the EU creates incentives for manufacturers to delay launch in low-price countries until higher prices have been established in other countries. The results of [Danzon et al., 2005] indicate that countries with lower expected prices or smaller expected market size have fewer launches and longer launch delays, controlling for per capita income and other country and firm characteristics. [Varol et al., 2012] conclude that product launch strategically takes place first in higher-priced EU markets as a result of threat of arbitrage and price dependency across the member states. [Kyle, 2007] found that companies delay launch into pricecontrolled markets, and are less likely to introduce their products in additional markets after entering a country with low prices.

These empirical analyses do not distinguish between the various existing IRP modalities. In particular, the composition of the basket of reference countries and the possible retroactivity of IRP are left apart. Neither do existing empirical papers make a difference between the determinants of launch delays and those of absence of launch, except [Lanjouw, 2005] who concludes that the standard argument regarding price regulation that it will dissuade market entry - appears to have more relevance among the high-income countries. For these countries, extensive price control is always found to lower the probability of market entry, and moderate regulation appears to do likewise, even in the long run. Not so for the poorer countries. There she finds that while price regulation makes 
it less likely that new drugs will be available quickly, it does not appear to prevent new products from being launched eventually.

The present paper is the only one that analyzes the firms' pricing and timing optimal responses to IRP in a general dynamic setting. We focus on IRP that takes the minimum price in the reference countries as the price cap. Our paper uniquely provides a benchmark solution to the firms' behavior under IRP when all countries reference the prices in all other countries and in all previous periods of time. First, there is no withdrawal of drugs in any country in any period of time. Second, there is no strict incentive to delay the launch of a drug in any country. Third, whenever the drug is sold in a country, it is also sold in all countries with larger willingness to pay (WTP). In other words, when the basket of reference countries is complete (all countries reference each other) and the IRP is retroactive, a profit-maximizing firm has no incentive to strategically delay launches of new drugs. The firm is better-off foregoing sales in low-price markets forever to sustain high profits in high-price markets from the very beginning.

The rationale for this "now or never" optimal timing strategy is the following. When deciding whether to launch a new drug in a country today rather than later, the firm tradesoff the profits from selling in that country today against the losses from propagating for ever the price of that country to all the other countries that would have paid higher prices otherwise. The trade off goes in favor of today if the country's market is large enough or if its WTP for the new drug is high enough. Otherwise, it is better to delay the launch in that country. Until when is it better for the firm to delay? The answer is forever because the trade off is actually repeated in every period: If it is better to delay the launch in a country once, then it is better to delay the launch all the time. This result is based on the ability of a price to propagate into other markets. Therefore, all the countries willing to pay a price above a given threshold are served while the others are not.

These benchmark results do not necessarily hold when either the basket of reference 
countries is incomplete or the international referencing is not retroactive. We use counter examples to make this point. When the countries only reference a subset of all other countries, the interdependence between the different markets is weaker and the firm can break some possible interdependencies by foregoing sales in some markets that are pivotal (pivotal because referenced by many and referencing many). Such a break, when optimal for the firm, does not need to be permanent. This motivates that none of the benchmark results holds when the set of reference countries is incomplete. Moreover, in this case, we show that the firm's profit is higher when the set of reference countries is incomplete rather than complete because there are fewer restrictions on prices.

When reference pricing is not retroactive and sales can be disrupted, it can be optimal for the firm to disrupt sales everywhere every second period so as to set the highest possible prices everywhere during the selling periods. Therefore, both withdrawing and postponing sales in markets can be optimal if reference pricing is not retroactive. Only one of the benchmark results holds now as long as the set of reference countries is complete, that is, whenever the drug is sold in a country, it is also sold in all countries with larger WTPs.

The remainder of this paper is structured as follows. We discuss informally an illustrative example in Section 2. The formal model and results are displayed in Section 3. Section 4 concludes. All proofs and technically usefull lemmas are in Appendix.

\section{An illustrative example}

We consider a monopolistic international firm selling a drug produced with no cost and a set of three countries $\{1,2,3\}$ in which the drug can be sold. In any country $i \in\{1,2,3\}$, the volume sold by the seller is $\omega_{i}$ if the drug is reimbursed by health authorities. Otherwise, no volume is sold. All countries have a willingness to pay $w_{i}$, independent of the prices in all countries, or free of context. In any country $i \in\{1,2,3\}$, consider the following policy: the drug is reimbursed by health authorities if 1) the price is lower than $w_{i}$, and 2) the 
price is not higher than a reference price that is, if it exists, the minimum of the prices set in all countries in the past. ${ }^{1}$

Now assume that $w_{1}=1, w_{2}=2$ and $w_{3}=3$. The seller's intent is to maximize its profit over the set of price vectors, the latter being understood as a sequence of prices for each country and for each period of time. Selling ${ }^{2}$ in all countries from the first period (at prices 1 in country 1, 2 in country 2 and 3 in country 3 in order to maximize the profit) might be a good start for an optimal strategy. However, implementing a price vector starting this way implies setting in the first period a reference price of 1 for future sales. Indeed, the price set in the first period in country 1 will be used as a reference price in all the other countries in the following periods. Then, in this case, selling in all countries, compared to selling only in countries 2 and 3, for instance, would induce more profit in the first period because of the larger sales volume but a decrease in the subsequent periods because of a lower price. Obviously, this argument is not valid if we think of selling only in countries 1 and 3 . In this case, the negative effect of setting a low price in a country that will be used as a reference price is still existing and some volume is lost. Then, we could argue that the question of entering a market or not is of concern only for the countries with the lowest $w$. This discussion suggests our first question:

i) Is it always the case that if the drug is sold in a country, it is sold in all countries with a higher $w$ ?

In the previous paragraph, we compared only very simple strategies. There might be some more complex optimal ones. Assume the same example as the one given above with the only difference that country 3 does not use country 1 as a reference country, i.e., a country whose price can be used as a reference price. Then, the problem of not spreading

\footnotetext{
${ }^{1}$ We do not explicitly model any bargaining process and take this policy as exogenous and based on implicit (or sometimes explicit) rules used by most health authorities in the world.

${ }^{2}$ In this article, by "selling in a country", we will mean "setting a price such that a strictly positive volume is sold in this country".
} 
the low price of country 1 might have another solution: it would be possible to not sell the drug in country 2, hence, keeping the sales in country 3 at price 3 for all times at the expense of not selling in country 2. But then, more generally, if the price in country 2 decreases with time because of the low prices in its reference countries, it could be imagined that it is worth selling the drug in country 2 for some time and then withdraw the drug from country 2's market after some time. This suggests our second question:

ii) Are there some optimal price vectors such that the drug is withdrawn from a country,

i.e. in some country, the drug is sold at a given period of time and it is not sold in a subsequent period?

Finally, since we just asked the problem of the dynamics of the price vector, we are also interested in the same dynamics but with a delayed introduction rather than in the form of a withdrawal. This is what is usually observed as "sequential launches".

iii) Are there some optimal price vectors with sequential launches, i.e., such that the drug is sold in a country at some period but it is not in the first?

As we will see, when all countries are reference countries for all countries, the answer to question i) is "Yes", to question ii) is: "No", and the answer to question iii) is "There may be but there always exists an optimal price vector with no sequential launches".

As we saw in the example described above, the structure of the sets of reference countries is of importance. And indeed, when the reference countries sets are not necessarily all countries, all the results enumerated above are not valid any longer.

We will also study the case of a limited time international reference pricing in the sense that in any country $i$, only the prices in the previous period and in the set of countries that are reference countries to $i$ can be used as reference prices. As we will see, in this case too, there exist no systematic results except for question i) and still, only in the case in which the reference countries sets of all countries are complete. 


\section{The model}

We consider in different settings the optimal price vectors for a monopolistic firm offering a drug for the international market. We consider with no lack of generality that the cost of production for the drug is null. Buyers are countries or the health authorities in each of the countries. We assume that the drug is sold in all countries with perfect segmentation. Said differently, there is no parallel imports. Let $N=(1, \ldots, N)$ be the set of countries. ${ }^{3}$ Each country $i$ has a willingness to pay (WTP), $w_{i}$, that is the price above which it is not ready to buy the drug under any circumstances. Let $\left(w_{1}, \ldots, w_{N}\right) \in \mathbb{R}^{+* N}$ be the WTPs for all countries. ${ }^{4}$ Each country $i$ is also characterized by a market size (MS), $\omega_{i}$. This is the quantity the seller can sell in country $i$ if country $i$ buys the drug. Let $\left(\omega_{1}, \ldots, \omega_{N}\right) \in \mathbb{R}^{+*}{ }^{N}$ be the MSs for all countries. ${ }^{5}$ Finally, each country $i$ uses a subset of countries (possibly all others countries) in order to compute a reference price at which it is willing to pay for the drug at a given time. We call these countries the Reference Countries (RCs) for country $i$ (or $i$ 's RCs set), denoted $R(i)$. Formally, $R$ is a function from $N$ onto $2^{N}$. We impose that countries are RCs for themselves: $\forall i \in N, i \in R(i)$.

The problem of the monopolistic seller is to maximize its profit over the price vectors $\left(p_{i}^{t}\right)_{i \in N, t \in \mathbb{N}}$ where $\forall i \in N, \forall t \in \mathbb{N}, p_{i}^{t} \in \mathbb{R}^{+}$. Then, we allow for prices that would change over time and countries. We consider discrete time and we denote $\beta$ the time discount rate of the seller.

\footnotetext{
${ }^{3}$ With a slight lack a rigor, but with no risk of confusion, $N$ is both the set of countries and its cardinality.

${ }^{4}$ As a general remark, we use superscripts for time indices and subscripts for country indices. $\mathbb{R}^{+}$ denotes the set of all positive real numbers. $\mathbb{R}^{+*}$ denotes the set of all positive real numbers excluding 0 . $\mathbb{N}$ denotes the set of all non-negative integers.

${ }^{5}$ Notice that, with no loss of generality, we don't consider countries with null WTP or MS. Such countries can just be considered non-existent by the seller.
} 


\subsection{Unlimited time referencing}

In this section, we assume the following constraints to the intertemporal maximization problem of the seller: at each period of time $t$, the quantity sold in country $i$ is $\omega_{i}$ if $p_{i}^{t}$ is smaller or equal to the minimum of: 1) $w_{i}$ and, 2) $\min _{t^{\prime}<t}\left(\min _{j \in R(i)} p_{j}^{t^{\prime}}\right)$ if $t>0$. Otherwise, 0 volume is sold. Then, the intertemporal maximization problem faced by the seller is

$$
\max _{\left(p_{i}^{t}\right)_{i \in N, t \in \mathbb{N}}} \sum_{t \in \mathbb{N}} \beta^{t}\left(\sum_{i \in S_{R}^{t}\left(\left(p_{j}^{t^{\prime}}\right)_{j \in N, t^{\prime} \in \mathbb{N}}\right)} p_{i}^{t} \cdot \omega_{i}\right) .
$$

where i) $S_{R}^{0}\left(\left(p_{j}^{t^{\prime}}\right)_{j \in N, t^{\prime} \in \mathbb{N}}\right)=\left\{i \in N, p_{i}^{0} \leq w_{i}\right\}$, ii) if $t>0, S_{R}^{t}\left(\left(p_{j}^{t^{\prime}}\right)_{j \in N, t^{\prime} \in \mathbb{N}}\right)=\left\{i \in N, p_{i}^{t} \leq\right.$ $\left.\min \left(w_{i}, \min _{j \in R(i), t^{\prime}<t}\left(p_{j}^{t^{\prime}}\right)\right)\right\}$.

Then, all the information required at each time to make a profit-maximization choice depends on the minimum of the prices in all countries in the periods before. Let $V$ : $\left(\mathbb{R}^{+}\right)^{N} \rightarrow \mathbb{R}$ with $V(p)$ the intertemporal profit earned by the seller if the minimum of the prices in all countries set in the history before the current period is $p \in\left(\mathbb{R}^{+}\right)^{N}$. Obviously, $V$ must satisfy the following Bellman equation:

$$
V(p)=\max _{p^{\prime} \in\left(\mathbb{R}^{+}\right)^{N}} \sum_{i \in O\left(p^{\prime}, p\right)} p_{i}^{\prime} \omega_{i}+\beta V \underline{\left(\left(p, p^{\prime}\right)\right)}
$$

where:

- $\forall p=\left(p_{1}, \ldots, p_{N}\right), p^{\prime}=\left(p_{1}^{\prime}, \ldots, p_{N}^{\prime}\right) \in\left(\mathbb{R}^{+}\right)^{N}, O\left(p^{\prime}, p\right)=\left\{i \in N, p_{i}^{\prime} \leq \min \left(w_{i}, \min _{j \in R(i)} p_{j}\right)\right\}$,

- $\forall p=\left(p_{1}, \ldots, p_{N}\right), p^{\prime}=\left(p_{1}^{\prime}, \ldots, p_{N}^{\prime}\right) \in\left(\mathbb{R}^{+}\right)^{N}, \underline{\left(p, p^{\prime}\right)} \in\left(\mathbb{R}^{+}\right)^{N}$ is defined by $\forall i \in N$,

$$
{\underline{\left(p, p^{\prime}\right.}}_{i}=\min \left(p_{i}, p_{i}^{\prime}\right)
$$

Then, maximizing Equation 1 is equivalent to maximize Equation 2 at each period with $p$ the minimum for each country of the prices ever set. Obviously, in the first period, we start with $p=\left(p_{1}, \ldots, p_{N}\right)$ and $\forall i \in N, p_{i}>\max _{j \in N} w_{j}$. 
Let $V^{a}:\left(\mathbb{R}^{+}\right)^{N} \rightarrow\left(\mathbb{R}^{+}\right)^{N}$ be the price vector ${ }^{6}$ that maximizes Equation 2 depending on the price vector at the start of the period. Formally,

$$
V^{a}(p)=\arg \max _{p^{\prime} \in\left(\mathbb{R}^{+}\right)^{N}} \sum_{i \in O\left(p^{\prime}, p\right)} p_{i}^{\prime} \omega_{i}+\beta V\left(\underline{\left(p, p^{\prime}\right)}\right) .
$$

\subsubsection{Complete RCs sets}

With a slight abuse in notation, and referring to the network formalism, we say that the RCs sets are complete when they equal $N$. Then, the first case we consider is the case in which all RCs sets are complete. Formally, $\forall i \in N, R(i)=N$.

We state the first feature of the optimal price vectors in the case we consider (unlimited time referencing and complete RCs sets). The following proposition states that there is no withdrawal of drugs in any country. Assume that the seller starts the current period (say, period A) with minimal prices in history $p$. Assume that in this case, its optimal pricing policy is $p^{\prime}$. Then, the next period (say, period B) will start with minimal prices in history $\underline{\left(p^{\prime}, p\right)}$. The following proposition formally states that any country where some strictly positive volume of the drug is sold in period A is also a country where some strictly positive volume of the drug is sold in period B.

\section{Proposition 1}

Assume $\forall i \in N, R(i)=N$. Let $p \in\left(\mathbb{R}^{+*}\right)^{N}$ and let $p^{\prime} \in V^{a}(p)$. Let $p^{\prime \prime} \in V^{a}\left(\underline{\left(p^{\prime}, p\right)}\right)$. $O\left(p^{\prime}, p\right) \subseteq O\left(p^{\prime \prime}, \underline{\left(p^{\prime}, p\right)}\right)$.

The following proposition states a second important feature of the optimal price vectors in the case we consider (unlimited time referencing and complete RCs sets). It shows that there is no strict incentive to delay the launch of the drug in any country. Assume that the seller starts the current period (say, period A) with minimal prices in history $p$. Assume that in this case, its optimal pricing policy is $p^{\prime}$. Then, the next period (say, period B) will

\footnotetext{
${ }^{6}$ Notice here that we have one price for each country but not for each period of time. With no risk of confusion, we call price vector a sequence of prices with time dimension or not, depending on the context.
} 
start with minimal prices in history $\left(p^{\prime}, p\right)$. The following proposition formally states that there exists an optimal pricing policy in period B for which exactly the countries where some strictly positive volume of the drug was sold in period A are the countries where some strictly positive volume of the drug is sold in period B. Said differently, there exists an optimal price vector with no sequential launches.

\section{Proposition 2}

Assume $\forall i \in N, R(i)=N$. Let $p \in \mathbb{R}^{+* N}$ and let $p^{\prime} \in V^{a}(p)$. Then, $\exists p^{\prime \prime} \in V^{a}\left(\underline{\left.\left(p, p^{\prime}\right)\right)}\right.$ such that $O\left(p^{\prime}, p\right)=O\left(p^{\prime \prime}, \underline{\left.\left(p^{\prime}, p\right)\right)}\right.$.

Finally, the following proposition states a third important feature of the optimal price vectors in the case we consider (unlimited time referencing and complete RCs sets). It states that whenever the drug is sold in a country, it is also sold in all countries with larger WTPs. This proposition relies on the fact that if the drug supplier sells in a country $j$ with WTP $w_{j}$ and not in a country $i$ with a larger WTP $w_{i}$, it can increase its instantaneous profit by selling in country $i$ - say at the same price at it sells in country $j$, which is possible since $w_{i} \geq w_{j}$ - without decreasing the minimum of the prices ever set in any country for the future periods and hence, without decreasing its future profits.

\section{Proposition 3}

Assume $\forall i \in N, R(i)=N$. Let $p \in \mathbb{R}^{+* N}$ and let $p^{\prime} \in V^{a}(p)$. Let $i, j \in N$ be such that $w_{i} \geq w_{j} . j \in O\left(p^{\prime}, p\right) \Rightarrow i \in O\left(p^{\prime}, p\right)$.

Then, we have proved three important features of the optimal price vectors in the case with unlimited time referencing and complete RCs sets. First, there is no withdrawal of the drug in any country where the drug has already been sold (Proposition 1). Second, there exists an optimal price vector for which all the countries where the drug is ever sold are the countries where the drug is sold from the first period (Proposition 2). Third, the countries where the drug is sold are the countries with the largest WTPs (Proposition 3). 


\subsubsection{Incomplete RCs sets}

In this section, we check the robustness of the propositions stated in the previous section for the case in which the RCs sets are not necessarily complete. Formally, we relax the following assumption: $\forall i \in N, R(i)=N$.

Let us consider the following example:

\section{EXAMPLE 1}

Let $\beta=0.9$. Let us consider a set of 3 countries: $N=\{1,2,3\}$ with WTPs $\left(w_{1}, w_{2}, w_{3}\right)=$ $(1,5,4)$, with $M S s\left(\omega_{1}, \omega_{2}, \omega_{3}\right)=(10,0.001,10)$ and with the following $R C$ sets: $R(1)=$ $\{1\}, R(2)=N$ and $R(3)=\{2,3\}$.

A simple computation shows that in Example 1, the optimal price vectors are the following:

- in period $0, p^{0}=\left(p_{1}^{0}, p_{2}^{0}, p_{3}^{0}\right)=(1,5,4)$,

- from period 1 on, $p^{1}=\left(p_{1}^{1}, p_{2}^{1}, p_{3}^{1}\right)=\left(1, p_{2}^{1}, 4\right)$, with $p_{2}^{1} \geq 4$.

One can see that in period 0 , the drug is sold in all countries. From period 1 on, it is sold only in countries 1 and 3 . Intuitively, the first objective of the seller in this case is to sell in country 3 , the country with the largest WTP and MS. Then, selling in country 1 is also possible since country 1 is not a RC for country 3 . However, selling in country 1 can be done if the seller makes sure that the low price in country 1 (country with a low WTP) is never used by country 3 to access a lower price. In order to do that, it is important not to have a low price in country 2 for which country 1 is a $\mathrm{RC}$. Then, the drug can be sold in country 2 but only in period 0 , before selling in this country means decreasing the price and provide country 3 with a low reference price. The optimal price vectors in Example 1 allows the seller to earn a profit equal to 500.005.

Using Example 1, it can be seen that Proposition 1 is not valid if all countries do not use all countries as RCs. Indeed, in this example, the drug is sold in country 2 only in 
period 0. After that, no volume is sold in country 2. Then, this is a situation of drug withdrawal.

The same example shows that Proposition 2 is not valid either if all countries do not use all countries as RCs. Indeed, in this example, there would be a strict loss of profit if the drug was sold only in countries 1 and 3 from period 0 . The small surplus profit from selling for 1 period in country 2 would be lost.

Finally, studying Example 1 shows that it is not necessarily interesting for the seller to sell the drug in the country with the highest WTP. Indeed, in Example 1, country 2 is the country with the highest WTP and still, always selling in this country would mean propagating low prices to countries with a lower WTP but a much larger MS.

Transposing Example 1 to the case with complete RCs sets, a simple computation shows that the optimal pricing strategy is to always sell in countries 2 and 3 with the following price vectors:

- in period $0, p^{0}=\left(p_{1}^{0}, p_{2}^{0}, p_{3}^{0}\right)=\left(p_{1}^{0}, 5,4\right)$, with $p_{1}^{0} \geq 4$,

- from period 1 on, $p^{1}=\left(p_{1}^{1}, p_{2}^{1}, p_{3}^{1}\right)=\left(p_{1}^{1}, 4,4\right)$, with $p_{1}^{1} \geq 4$.

This strategy gives the seller a profit equal to 400.041 instead.

The comparison between these two cases is an illustration of the following proposition that shows that when the set of RCs is larger (with respect to inclusion), profits decrease.

\section{Proposition 4}

Let $R, R^{\prime}: N \rightarrow 2^{N}$ be such that $\forall i \in N, i \in R(i)$ and $\forall i \in N, R(i) \subseteq R^{\prime}(i)$. Let $V$ be defined as in Equation 2 for $R$ and let $V^{\prime}$ be defined as in Equation 2 for $R^{\prime}$. Then, $\forall p \in \mathbb{R}+{ }^{N}, V(p) \geq V^{\prime}(p)$.

The intuition for this proposition is straightforward. When less countries are RCs, the constraints imposed on the price vectors are less binding and then, there is more possibility for the monopolistic seller to make larger profits. 
Example 1 shows that Proposition 2 is not satisfied because the drug is withdrawn from some markets. The next example shows that, on the contrary, there can be some cases in which all optimal price vectors are ones with sequential launches.

\section{EXAMPLE 2}

Let $\beta=0.9$. Let us consider a set of 4 countries: $N=\{1,2,3,4\}$ with WTPs $\left(w_{1}, w_{2}, w_{3}, w_{4}\right)=$ $(1,1,2,2)$, with MSs $\left(\omega_{1}, \omega_{2}, \omega_{3}, \omega_{4}\right)=(9,5.2,6.7,9)$ and with the following RCs sets: $R(1)=\{1,3\}, R(2)=\{2\}, R(3)=\{1,3\}$ and $R(4)=\{2,3,4\}$.

A simple computation shows that in Example 2, the optimal price vectors are the following:

- in period $0, p^{0}=\left(p_{1}^{0}, p_{2}^{0}, p_{3}^{0}, p_{4}^{0}\right)=\left(1, p_{2}^{0}, 2,2\right)$, with $p_{2}^{0} \geq 2$,

- in period $1, p^{1}=\left(p_{1}^{1}, p_{2}^{1}, p_{3}^{1}, p_{4}^{1}\right)=(1,1,1,2)$,

- from period 2 on, $p^{2}=\left(p_{1}^{2}, p_{2}^{2}, p_{3}^{2}, p_{4}^{2}\right)=(1,1,1,1)$.

Then, in Example 2, the drug is sold with strictly positive volumes in all countries at the maximum possible price at all periods but in period 0 where it is not sold in country 2 . The intuition is the following. It is optimal to sell the drug in all countries in the long term. However, it is also optimal to have a "slow" decrease of the price in country 4 that represents a quite large MS. In order to achieve this slow decrease of prices, it is important not to launch the drug in country 2 in period 0 . Since country 2 has a smaller MS than country 4 and since country 2 is taken as a RC by country 4 , selling in period 0 in country 2 would mean an increase in the instantaneous profit but it would mean a decrease in the price in period 1 in country 4 and hence, a loss of profit that would overcome the instantaneous gain in profit. However, notice that it is not worth keeping a high price in country 4 at all costs. This objective would mean not selling in country 2 at all and also keep a high price in country 3 , which in its turn would mean not selling in country 1 , a loss of profit that would not be worth keeping a high price in country 4 . 


\subsection{Limited time referencing}

We now consider that countries can use as reference prices only the prices in the previous period. Then, we assume the following constraints to the intertemporal maximization problem of the seller: at each period of time $t$, the quantity sold in country $i$ is $\omega_{i}$ if $p_{i}^{t}$ is inferior or equal to the minimum of: 1) $w_{i}$ and 2) $\min _{j \in R(i)} p_{j}^{t-1}$ if $t>0$. Otherwise, 0 volume is sold. Then, all the information required at each time to make a profit-maximization choice depends on the prices in all countries in the period just before the current one. Let $W:\left(R^{+}\right)^{N} \rightarrow \mathbb{R}$ with $W(p)$ the intertemporal profit earned by the seller if the prices in all countries set in the previous period is $p \in\left(R^{+}\right)^{N}$. Obviously, $W$ must satisfy the following Bellman equation:

$$
W(p)=\max _{p^{\prime} \in \mathbb{R}^{N}} \sum_{i \in O\left(p^{\prime}, p\right)} p_{i}^{\prime} \omega_{i}+\beta W\left(p^{\prime}\right)
$$

where

$$
\text { - } \forall p=\left(p_{1}, \ldots, p_{N}\right), p^{\prime}=\left(p_{1}^{\prime}, \ldots, p_{N}^{\prime}\right) \in \mathbb{R}^{N}, O\left(p^{\prime}, p\right)=\left\{i \in N, p_{i}^{\prime} \leq \min \left(w_{i}, \min _{j \in R(i)}\left(p_{j}\right)\right)\right\}
$$

Then maximizing the intertemporal seller's profit is equivalent to maximize Equation 3 at each period with $p$ the prices for each country in the preceding period. Obviously, in the first period, we start with $p=\left(p_{1}, \ldots, p_{N}\right)$ with $\forall i \in N, p_{i}>\max _{j \in N} w_{j}$.

Let $W^{a}:\left(\mathbb{R}^{+}\right)^{N} \rightarrow\left(\mathbb{R}^{+}\right)^{N}$ be the price vector that maximizes Equation 3 depending on the price vector at the start of the period. Formally,

$$
W^{a}(p)=\arg \max _{p^{\prime} \in\left(R^{+}\right)^{N}} \sum_{i \in O\left(p^{\prime}, p\right)} p_{i}^{\prime} \omega_{i}+\beta W\left(p^{\prime}\right) .
$$

The following example shows that neither Proposition 1 nor Proposition 2 are valid for function $W$. That is, there exist cases in which all the optimal price vectors imply that the drug is withdrawn from the market and even in a sense launched sequentially. Then, there exist no optimal price vectors such that the set of countries in which the drug is sold is constant from period 1 on. 


\section{EXAMPLE 3}

Let $\beta=0.9$. Let us consider a set of 5 countries: $N=\{1,2,3,4,5\}$ with WTPs $\left(w_{1}, w_{2}, w_{3}, w_{4}, w_{5}\right)=$ $(1,1,3,5,5)$, with MSs $\left(\omega_{1}, \omega_{2}, \omega_{3}, \omega_{4}, \omega_{5}\right)=(8,2,2,2,1.5)$ and with complete RCs sets: $R(1)=R(2)=R(3)=R(4)=R(5)=N$.

A simple computation shows that in Example 3, the optimal price vectors are the following:

- in period 0 and even periods, $p^{0}=\left(p_{1}^{0}, p_{2}^{0}, p_{3}^{0}, p_{4}^{0}, p_{5}^{0}\right)=(1,1,3,5,5)$,

- in odd periods, $p^{1}=\left(p_{1}^{1}, p_{2}^{1}, p_{3}^{1}, p_{4}^{1}, p_{5}^{1}\right)$ with $\min \left(p_{1}^{1}, p_{2}^{1}, p_{3}^{1}, p_{4}^{1}, p_{5}^{1}\right) \geq 5$.

Then, the optimal price vector is to set maximum prices with constraint of selling in even periods, and withdraw the drug from all countries in odd periods. The intuition goes as follows. In this case, it is better to remove the drug from the market of all countries for one period every two other so that prices can be set at their maximum with constraint of selling in even periods. The removal of the drug must be complete in order to have no binding reference price for no country in even periods. If the removal was not complete, the price in the remaining country would be 1 , and the profit in the even periods would be too low. Then, in Example 3, quantities are abandoned in odd periods in order to have high prices in even periods.

\subsubsection{Complete RCs sets}

In this section, as we did in the case of unlimited time referencing, we consider that all RCs sets are complete. Formally, $\forall i \in N, R(i)=N$. Example 3 already proved that Propositions 1 and 2 are not robust when only limited time referencing is considered even in the case of complete RCs sets.

On the contrary, the following proposition shows that Proposition 3 is still valid when we consider only limited time referencing. Then, when the drug is sold in a country at a given period, it is sold in all countries with greater WTPs. The intuition is the same as in the case with unlimited time referencing. 


\section{Proposition 5}

Let $p \in \mathbb{R}^{+* N}$ and let $p^{\prime} \in W^{a}(p)$. Let $i, j \in N$ be such that $w_{i} \geq w_{j} . j \in O\left(p^{\prime}, p\right) \Rightarrow i \in$ $O\left(p^{\prime}, p\right)$.

\subsubsection{Incomplete RCs sets}

We have seen that only Proposition 3, adapted in Proposition 5 for limited time referencing, is robust when RCs sets are complete. The following example shows that again, this is not true anymore for incomplete RCs sets. Proposition 5 is not valid when RCs sets are incomplete and time referencing is limited, just as Proposition 3 is not valid when RCs sets are incomplete and time referencing is unlimited.

\section{EXAMPLE 4}

$\beta=0.9$. Let us consider a set of 4 countries: $N=\{1,2,3,4\}$ with WTPs $\left(w_{1}, w_{2}, w_{3}, w_{4}\right)=$ $(1,2,2,3)$, with MSs $\left(\omega_{1}, \omega_{2}, \omega_{3}, \omega_{4}\right)=(6.5,5.5,9,0.5)$ and with the following RCs sets: $R(1)=N, R(2)=N, R(3)=\{3,4\}$ and $R(4)=\{1,3,4\}$.

A simple computation shows that in Example 4, the optimal price vectors are the following:

- in period $0, p^{0}=\left(p_{1}^{0}, p_{2}^{0}, p_{3}^{0}, p_{4}^{0}\right)=(1,2,2,3)$,

- in period 1 on, $p^{1}=\left(p_{1}^{1}, p_{2}^{1}, p_{3}^{1}, p_{4}^{1}\right)=\left(1,1,2, p_{4}^{1}\right)$, with $p_{4}^{1} \geq 2$.

Then, in this case, selling strictly positive volumes in all countries is important but it is also important not to decrease the price in country 3 which represent a large MS. In order not to do that, it is crucial that country 4 does not propagate a low price since country 4 is a RC for country 3. And country 4 could propagate a low price coming from country 1. Then, selling the drug in country 4 for one period is acceptable since one period is not enough to propagate the low price implemented in country 1. Afterward, the country with the highest WTP (country 4) is abandoned by the seller because it represents a too small MS compared to the decrease in prices a sale there would imply. 
Finally, we show that it is possible to generalize Proposition 4 to the case with only limited time referencing, the intuition being unchanged.

\section{Proposition 6}

Let $R, R^{\prime}: N \rightarrow 2^{N}$ be such that $\forall i \in N, i \in R(i)$ and $\forall i \in N, R(i) \subseteq R^{\prime}(i)$. Let $W$ be defined as in Equation 3 for $R$ and let $W^{\prime}$ be defined as in Equation 3 for $R^{\prime}$. Then, $\forall p \in \mathbb{R}+{ }^{N}, W(p) \geq W^{\prime}(p)$.

\section{Conclusion}

To the best of our knowledge, the present paper is the first one to offer theoretical results linking IRP and timing of launches in a general dynamic setting. It identifies a useful benchmark case with three clear theoretical results when time referencing is unlimited and the set of reference countries is complete: First, there is no withdrawal of the drug in any country where the drug has already been sold (Proposition 1). Second, there exists an optimal price vector for which all the countries where the drug is ever sold are the countries where the drug is sold from the first period (Proposition 2). Third, the countries where the drug is sold are the countries with the largest WTPs (Proposition 3).

We also show in this paper that these results are not necessarily robust to a departure from the benchmark case. In particular, none of them holds when countries only reference the prices of a subset of other countries. In that case, the firm may be better-off foregoing some markets for a while to break the interdependence of prices between the countries. Furthermore, when international referencing is not retroactive, it might become optimal for the firm to regularly interrupt sales in every country so as to bring all the prices back to their highest levels.

These benchmark results as well as the counter examples when departing from the benchmark situation can prove very useful for regulating authorities to anticipate the effects of different IRP modalities. They may also help empirical analyses to explain why 
some drugs never reach the consumers in some markets while they reach them at a late date in other markets.

Let us end our study with a few remarks. First, as is usually done in applied studies in the pharmaceutical industry, we did not introduce any dynamics inside each country such as market penetration that would be time-dependent. Introducing such a new dimension would possibly modify the incentives to not delay the launch of a drug by decreasing the WTPs in the beginning of the drug selling period. Second, we only considered minimum price references as cap prices. In reality, reference prices can be considered in more complex terms. Finally, we did not consider any cost for the pharmaceutical firm. Such a cost by itself would not change our results. However, it would change them if coupled with some liquidity constraints. Then, it would be possible that launching in only a part of the countries would have the effect of accumulating enough resources to pay for important fixed costs in countries in which the drug would be launched subsequently. 


\section{References}

[Danzon and Epstein, 2008] Danzon P.M. and Epstein A.J. (2008) "Effects of regulation on drug launch and pricing in interdependent markets", NBER Working Paper 14041.

[Danzon et al., 2005] Danzon P.M., Wang Y.R. and Wang L. (2005) "The impact of price regulation on the launch delay of new drugs - evidence from twenty-five major markets in the 1990s", Health Economics 14: 269-292.

[Kyle, 2007] Kyle M.K. (2007) "Pharmaceutical price controls and entry strategies", Review of Economics and Statistics 89(1): 88-99.

[Lanjouw, 2005] Lanjouw J.O. (2005) "Patents, price controls and access to new drugs: How policy affects global market entry", NBER Working Paper 11321.

[Rankin, 2003] Rankin P.J. (2003) The pharmaceutical Pricing Compendium 1st Edition. London: Urch Publishing.

[Richter, 2008] Richter A. (2008) "Assessing the impact of global price interdependencies", Pharmacoeconomics 26(8): 649-659.

[Varol et al., 2012] Varol N., Costa-Font J. and McGuire A. (2012) "Does adoption of pharmaceutical innovation respond to changes in the regulatory environment?", Applied Economic Perspectives and Policy, Agricultural and Applied Economics Association 34(3): 531-553. 


\section{A Appendix}

\section{A.1 Unlimited time referencing}

By assumption, the price in country $i$ is limited by its WTP, $w_{i}$, and the history of prices in countries $R(i)$, summarized by the minimum of the prices ever set in $R(i)$. Then, relaxing these minimums leads to an intertemporal profit that cannot decrease. This is formally expressed in the following lemma.

\section{LEMMA 1}

Let $p, p^{\prime} \in \mathbb{R}^{N}$ be such that $\forall i \in N, p_{i} \geq p_{i}^{\prime}$. Then, $V(p) \geq V\left(p_{i}^{\prime}\right)$.

Proof of Lemma 1: Let $p^{\prime \prime} \in V^{a}\left(p^{\prime}\right)$. Let $p^{\prime \prime \prime}=\underline{\left(p^{\prime \prime}, p^{\prime}\right)}$. By definition, $\forall i \in O\left(p^{\prime \prime}, p^{\prime}\right)$, $p_{i}^{\prime \prime} \leq w_{i}$ and $p_{i}^{\prime \prime} \leq \min _{j \in R(i)} p_{j}^{\prime}$. Then, $\forall i \in O\left(p^{\prime \prime}, p^{\prime}\right), p_{i}^{\prime \prime \prime} \leq p_{i}^{\prime \prime} \leq w_{i}$ and $p_{i}^{\prime \prime \prime} \leq p_{i}^{\prime \prime} \leq$ $\min _{j \in R(i)} p_{j}^{\prime} \leq \min _{j \in R(i)} p_{j}$. Then, $O\left(p^{\prime \prime}, p^{\prime}\right) \subseteq O\left(p^{\prime \prime \prime}, p\right)$. Moreover, since $\forall i \in N, p_{i} \geq p_{i}^{\prime}$, $\underline{\left(p^{\prime \prime \prime}, p\right)}=p^{\prime \prime \prime}=\underline{\left(p^{\prime \prime}, p^{\prime}\right)}$. Then, $V(p) \geq \sum_{i \in O\left(p^{\prime \prime \prime}, p\right)} p_{i}^{\prime \prime \prime} \omega_{i}+\beta V\left(\underline{\left(p^{\prime \prime \prime}, p\right)}\right)=\sum_{i \in O\left(p^{\prime \prime \prime}, p\right)} p_{i}^{\prime \prime \prime} \omega_{i}+$ $\beta V\left(\underline{\left(p^{\prime \prime}, p^{\prime}\right)}\right)$. Moreover, $\forall i \in O\left(p^{\prime \prime}, p^{\prime}\right), p_{i}^{\prime \prime} \leq \min _{j \in R(i)} p_{j}^{\prime} \leq p_{i}^{\prime}$. Then, $\forall i \in O\left(p^{\prime \prime}, p^{\prime}\right), p_{i}^{\prime \prime \prime}=$

$p_{i}^{\prime \prime}$. Hence, $\sum_{i \in O\left(p^{\prime \prime \prime}, p\right)} p_{i}^{\prime \prime \prime} \omega_{i}+\beta V\left(\underline{\left(p^{\prime \prime}, p^{\prime}\right)}\right) \geq \sum_{i \in O\left(p^{\prime \prime}, p^{\prime}\right)} p_{i}^{\prime \prime} \omega_{i}+\beta V\left(\underline{\left(p^{\prime \prime}, p^{\prime}\right)}\right)=V\left(p^{\prime}\right)$. Then, $V(p) \geq V\left(p^{\prime}\right)$.

The following lemma shows that unless some prices have already been set at 0 in the past, the monopoly is never interested in setting 0 price in any country. Remember that all WTPs and MSs are strictly positive and then, setting 0 prices is just a loss of revenue.

\section{LEMMA 2}

Let $p \in \mathbb{R}^{N}$ be such that $\forall i \in N, p_{i}>0$ and let $p^{\prime} \in V^{a}(p)$. Then, $\forall i \in N, p_{i}^{\prime}>0$.

Proof of Lemma 2: Assume $p^{\prime} \in V^{a}(p)$ with $p_{i}^{\prime}=0$ for some $i \in N$. Let us consider $p^{\prime \prime} \in \mathbb{R}^{N}$ defined by:

$$
\forall k \in N, p_{k}^{\prime \prime}=\left\{\begin{array}{ll}
\min \left(w_{i}, \min _{j \in N} p_{j}\right), & \text { if } k=i \\
p_{k}^{\prime}, & \text { otherwise }
\end{array} .\right.
$$


Obviously, $O\left(p^{\prime \prime}, p\right)=O\left(p^{\prime}, p\right)$ and $p_{i}^{\prime \prime}>0$. Then, $\sum_{j \in O\left(p^{\prime \prime}, p\right)} p_{j}^{\prime \prime} \omega_{j}+\beta V\left(\underline{\left(p^{\prime \prime}, p\right)}\right)>\sum_{j \in O\left(p^{\prime}, p\right)} p_{j}^{\prime} \omega_{j}+$ $\beta V\left(\underline{\left(p^{\prime \prime}, p\right)}\right)$. By Lemma 1, $V\left(\underline{\left(p^{\prime \prime}, p\right)}\right) \geq V\left(\underline{\left(p^{\prime}, p\right)}\right)$. Hence, $\sum_{j \in O\left(p^{\prime \prime}, p\right)} p_{j}^{\prime \prime} \omega_{j}+\beta V\left(\underline{\left(p^{\prime \prime}, p\right)}\right)>$ $\sum_{j \in O\left(p^{\prime}, p\right)} p_{j}^{\prime} \omega_{j}+\beta V\left(\underline{\left(p^{\prime}, p\right)}\right)=V(p)$ contradicting the fact that $p^{\prime} \in V^{a}(p)$.

\section{A.1.1 Complete RCs sets}

Obviously, by definition, what matters in the setting of prices at any period of time is the minimum of the prices in all countries in all the previous periods. We omit the proof of the following lemma. It is available upon request from the authors.

\section{LEMMA 3}

Assume $\forall i \in N, R(i)=N$. Let $p, p^{\prime} \in \mathbb{R}^{N}$ be such that $\min _{j \in N} p_{j}=\min _{j \in N} p_{j}^{\prime} . V^{a}(p)=$ $V^{a}\left(p^{\prime}\right)$.

The following lemma states that if the vector of prices at the start of the period is $p$ and the seller does not sell in a country $i$ in the same period, it is because, in the current and past periods, no price has ever been smaller than country $i$ 's WTP. The reason is the following: assume there has already been or there currently is a price set in a country below $w_{i}$. Then, selling in country $i$ at the minimum price ever seen, increases the profit earned by the seller in the current period and it does not necessarily harm its future payoff, since the price in country $i$ is not lower than the minimum price ever set in any country.

\section{LEMMA 4}

Assume $\forall i \in N, R(i)=N$. Let $p \in \mathbb{R}^{+* N}$ and let $p^{\prime} \in V^{a}(p) . \forall i \in N, i \notin O\left(p^{\prime}, p\right) \Rightarrow$ $\min _{j \in N}\left({\underline{\left(p^{\prime}, p\right)}}_{j}\right)>w_{i}$.

Proof of Lemma 4: Assume it is not the case: let $i \in N$ be such that $i \notin O\left(p^{\prime}, p\right)$ and $\min _{j \in N}\left({\underline{\left(p^{\prime}, p\right)}}_{j}\right) \leq w_{i}$. Let us consider $p^{\prime \prime} \in \mathbb{R}^{N}$ defined by:

$$
\forall k \in N, p_{k}^{\prime \prime}=\left\{\begin{array}{ll}
\min _{j \in N}\left(\underline{\left(p, p^{\prime}\right)} j\right), & \text { if } k=i \\
p_{k}^{\prime}, & \text { otherwise }
\end{array} .\right.
$$


Obviously, $\left.\min _{j \in N}\left(\underline{\left(p, p^{\prime}\right)}\right)_{j}\right)=\min _{j \in N}\left({\underline{\left(p, p^{\prime \prime}\right)}}_{j}\right)$. Then, by Lemma 3, $V(p)=\sum_{j \in O\left(p^{\prime}, p\right)} p_{j}^{\prime} \omega_{j}+$ $\beta V\left(\underline{\left(p^{\prime}, p\right)}\right)=\sum_{j \in O\left(p^{\prime}, p\right)} p_{j}^{\prime} \omega_{j}+\beta V\left(\underline{\left(p^{\prime \prime}, p\right)}\right)$. Moreover, by assumption, $p_{i}^{\prime \prime}=\min _{j \in N}{\underline{\left(p, p^{\prime}\right)}}_{j} \leq$ $w_{i}$ and $p_{i}^{\prime \prime}=\min _{j \in N} \underline{\left(p, p^{\prime}\right)} j \leq \min _{j \in N} p_{j}$. Hence, $O\left(p^{\prime \prime}, p\right)=O\left(p^{\prime}, p\right) \cup\{i\}$. By Lemma 2, $p_{i}^{\prime \prime}>0$. Hence, $V(p)<\sum_{j \in O\left(p^{\prime \prime}, p\right)} p_{j}^{\prime \prime} \omega_{j}+\beta V\left(\underline{\left(p^{\prime \prime}, p\right)}\right)$. This contradicts the assumption that $p^{\prime} \in V^{a}(p)$.

\section{LEMMA 5}

Assume $\forall i \in N, R(i)=N$. Let $p \in \mathbb{R}^{+* N}$ and let $p^{\prime} \in V^{a}(p)$. Then, $O\left(p^{\prime}, p\right)=$ $O\left(p^{\prime}, \underline{\left.\left(p, p^{\prime}\right)\right)}\right.$.

Proof of Lemma 5: Let $i \notin O\left(p^{\prime}, p\right)$. By Lemma 4, $\min _{j \in N}\left(\underline{\left.\left(p^{\prime}, p\right)_{j}\right)}>>w_{i}\right.$. Hence, $p_{i}^{\prime}>w_{i}$ which implies $i \notin O\left(p^{\prime}, \underline{\left(p, p^{\prime}\right)}\right)$.

Let $i \notin O\left(p^{\prime}, \underline{\left(p, p^{\prime}\right)}\right)$. Then, i) $p_{i}^{\prime}>w_{i}$ in which case $i \notin O\left(p^{\prime}, p\right)$ or ii) $p_{i}^{\prime}>\min _{j \in N} \underline{\left(p, p^{\prime}\right)}$ j. In case ii), $p_{i}^{\prime}>\min _{j \in N} p_{j}$ which implies $i \notin O\left(p^{\prime}, p\right)$.

Proof of Proposition 1: By Lemma 2, $p^{\prime} \in \mathbb{R}^{+* N}$ and then, $\underline{\left(p^{\prime}, p\right)} \in \mathbb{R}^{+* N}$. Let us have $i \notin O\left(p^{\prime \prime}, \underline{\left(p^{\prime}, p\right)}\right)$. By Lemma $4, \min _{j \in N}\left({\underline{\left(p^{\prime \prime}, \underline{(p)}^{\prime}, p\right)}}_{j}\right)>w_{i}$. This implies $p_{i}^{\prime}>w_{i}$. Hence, by definition, $i \notin O\left(p^{\prime}, p\right)$.

Proof of Proposition 2: Let $p^{\prime \prime \prime} \in V^{a}\left(\underline{\left(p, p^{\prime}\right)}\right)$. By Lemma $2, p^{\prime} \in \mathbb{R}^{+*^{N}}$ and then, $\underline{\left(p^{\prime}, p\right)} \in \mathbb{R}^{+* N}$. Let us assume the proposition is not true, $\forall p^{\prime \prime} \in V^{a}\left(\underline{\left(p, p^{\prime}\right)}\right), O\left(p^{\prime}, p\right) \neq$ $O\left(p^{\prime \prime}, \underline{\left(p^{\prime}, p\right)}\right)$. By Lemma $5, O\left(p^{\prime}, p\right)=O\left(p^{\prime}, \underline{\left(p^{\prime}, p\right)}\right)$. Then, by assumption, we must have $p^{\prime} \notin V^{a}\left(\underline{\left(p, p^{\prime}\right)}\right)$. Hence,

$$
\sum_{i \in O\left(p^{\prime}, \underline{\left.\left(p, p^{\prime}\right)\right)}\right.} p_{i}^{\prime} \omega_{i}+\beta V\left(\underline{\left(p, p^{\prime}\right)}\right)<\sum_{i \in O\left(p^{\prime \prime \prime}, \underline{\left.\left(p, p^{\prime}\right)\right)}\right.} p_{i}^{\prime \prime \prime} \omega_{i}+\beta V\left(\underline{\left(p^{\prime \prime \prime}, \underline{\left(p, p^{\prime}\right)}\right)}\right)=V\left(\underline{\left(p, p^{\prime}\right)}\right) .
$$

Then, by Lemma 5 ,

$$
\sum_{i \in O\left(p^{\prime}, p\right)} p_{i}^{\prime} \omega_{i}+\beta V\left(\underline{\left(p, p^{\prime}\right)}\right)<V\left(\underline{\left(p, p^{\prime}\right)}\right) .
$$

Hence,

$$
V(p)<V\left(\underline{\left(p, p^{\prime}\right)}\right) .
$$


Let us have $i \in O\left(p^{\prime \prime \prime}, \underline{\left(p, p^{\prime}\right)}\right)$. By definition, this implies $p_{i}^{\prime \prime \prime} \leq w_{i}$ and $p_{i}^{\prime \prime \prime} \leq \min _{j \in N}{\underline{\left(p, p^{\prime}\right)}}_{j} \leq$ $\min _{j \in N} p_{j}$. Hence, $i \in O\left(p^{\prime \prime \prime}, p\right)$. Then,

$$
\sum_{i \in O\left(p^{\prime \prime \prime}, \underline{\left.\left(p, p^{\prime}\right)\right)}\right.} p_{i}^{\prime \prime \prime} \omega_{i} \leq \sum_{i \in O\left(p^{\prime \prime \prime}, p\right)} p_{i}^{\prime \prime \prime} \omega_{i}
$$

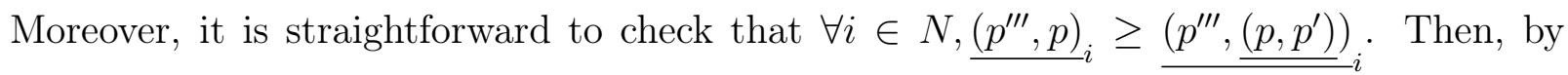
Lemma 1,

$$
V\left(\underline{\left.\left(p^{\prime \prime \prime}, \underline{\left(p, p^{\prime}\right)}\right)\right)} \leq V\left(\underline{\left(p^{\prime \prime \prime}, p\right)}\right) .\right.
$$

Hence,

$$
V(p)<\sum_{i \in O\left(p^{\prime \prime \prime}, p\right)} p_{i}^{\prime \prime \prime} \omega_{i}+\beta V\left(\underline{\left(p^{\prime \prime \prime}, p\right)}\right)
$$

which contradicts the fact that $p^{\prime} \in V^{a}(p)$.

Proof of Proposition 3: Assume it is not the case, let us have $j \in O\left(p^{\prime}, p\right)$ and $i \notin O\left(p^{\prime}, p\right)$. By Lemma 4, $i \notin O\left(p^{\prime}, p\right)$ implies $\left.\min _{j \in N}\left(\underline{\left(p^{\prime}, p\right)}\right)_{j}\right)>w_{i}$. Then, $p_{j}^{\prime} \geq$ $\min _{j \in N}\left({\underline{\left(p^{\prime}, p\right)}}_{j}\right)>w_{i} \geq w_{j}$. Then, by definition, $j \notin O\left(p^{\prime}, p\right)$ which contradicts the assumption that $j \in O\left(p^{\prime} p\right)$.

\section{A.1.2 Incomplete RCs sets}

Proof of Proposition 4: Let

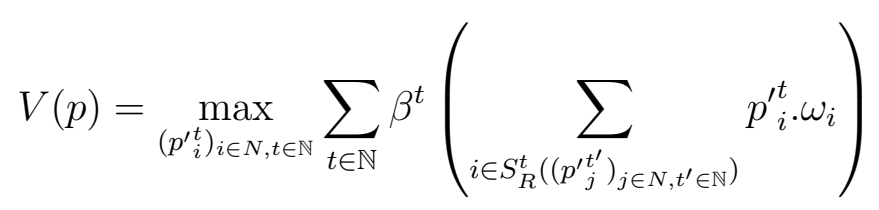

and let

$$
V^{\prime}(p)=\max _{\left(p_{i}^{t}{ }_{i}\right)_{i \in N, t \in \mathbb{N}}} \sum_{t \in \mathbb{N}} \beta^{t}\left(\sum_{i \in S_{R^{\prime}}^{t}\left(\left(p^{t^{\prime}{ }_{j}^{\prime}}\right)_{j \in N, t^{\prime} \in \mathbb{N}}\right)} p_{i}^{\prime t} \cdot \omega_{i}\right) .
$$

with $\forall i \in N, \forall t \in \mathbb{N}$, i) if $t=0, i \in S_{R}^{t}\left(\left(p_{j}^{t^{\prime}}\right)_{j \in N, t^{\prime} \in \mathbb{N}}\right) \Leftrightarrow p_{i}^{t} \leq \min \left(w_{i}, \min _{j \in R(i)}\left(p_{j}\right)\right)$, ii) if $t>0, i \in S_{R}^{t}\left(\left(p_{j}^{t^{\prime}}\right)_{j \in N, t^{\prime} \in \mathbb{N}}\right) \Leftrightarrow p_{i}^{t} \leq \min \left(w_{i}, \min _{j \in R(i), t^{\prime}<t}\left(p_{j}^{t^{\prime}}\right), \min _{j \in R(i)}\left(p_{j}\right)\right)$ (the same definition applies with $R^{\prime}$ ). 
Let $\left(p^{\prime \prime t}\right)_{i \in N, t \in \mathbb{N}}$ be an optimal price sequence maximizing in Equation 4. By assumption, $\forall i \in N, R(i) \subseteq R^{\prime}(i)$. Then, by definition, $\forall t \in \mathbb{N}, \forall i \in N, S_{R^{\prime}}^{t}\left(\left(p_{j}^{t^{\prime}}\right)_{j \in N, t^{\prime} \in \mathbb{N}}\right) \subseteq$ $S_{R}^{t}\left(\left(p_{j}^{t^{\prime}}\right)_{j \in N, t^{\prime} \in \mathbb{N}}\right)$. Then, $\sum_{t \in \mathbb{N}} \beta^{t}\left(\sum_{i \in S_{R}^{t}\left(\left(p^{\prime \prime t^{\prime}}{ }_{j}\right)_{j \in N, t^{\prime} \in \mathbb{N}}\right)} w_{i} \cdot \omega_{i}\right) \geq \sum_{t \in \mathbb{N}} \beta^{t}\left(\sum_{\left.i \in S_{R^{\prime}}^{t}\left(p^{\prime \prime \prime}{ }_{j}^{\prime}\right)_{j \in N, t^{\prime} \in \mathbb{N}}\right)} w_{i} \cdot \omega_{i}\right)$. Then, $V>V^{\prime}$.

\section{A.2 Limited time referencing}

\section{A.2.1 Complete RCs sets}

Obviously,by definition, what matters in the setting of prices at any period of time is the minimum of the prices in all countries in the previous period. We omit the proof of the following lemma.

\section{LEMMA 6}

Assume $\forall i \in N, R(i)=N$. Let $p, p^{\prime} \in \mathbb{R}^{N}$ be such that $\min _{j \in N} p_{j}=\min _{j \in N} p_{j}^{\prime} . W^{a}(p)=$ $W^{a}\left(p^{\prime}\right)$.

\section{LEMMA 7}

Let $p \in \mathbb{R}^{N}$ be such that $\forall i \in N, p_{i}>0$ and let $p^{\prime} \in V^{a}(p)$. Then, $\forall i \in N, p_{i}^{\prime}>0$.

Proof of Lemma 7: The proof is similar to the proof of Lemma 2 and therefore is omitted.

Proof of Proposition 5: Let us assume it is not the case: $j \in O\left(p^{\prime}, p\right)$ and $i \notin O\left(p^{\prime}, p\right)$. Let us consider $p^{\prime \prime} \in \mathbb{R}^{N}$ defined by:

$$
\forall k \in N, p_{k}^{\prime \prime}=\left\{\begin{array}{ll}
\min _{l \in N}\left(p_{l}^{\prime}\right), & \text { if } k=i \\
p_{k}^{\prime}, & \text { otherwise }
\end{array} .\right.
$$

By definition, $\min _{l \in N}\left(p_{l}^{\prime}\right)=\min _{l \in N}\left(p_{l}^{\prime \prime}\right)$ and then, by Lemma $6, W\left(p^{\prime}\right)=W\left(p^{\prime \prime}\right) . \quad j \in$ $O\left(p^{\prime}, p\right)$ implies $p_{j}^{\prime} \leq w_{j}$ and $p_{j}^{\prime} \leq \min _{l \in N}\left(p_{l}\right)$. Then, $\min _{l \in N}\left(p_{l}^{\prime}\right) \leq p_{j}^{\prime} \leq w_{j} \leq w_{i}$ and $\min _{l \in N}\left(p_{l}^{\prime}\right) \leq p_{j}^{\prime} \leq \min _{l \in N}\left(p_{l}\right)$. Then, $O\left(p^{\prime \prime}, p\right)=O\left(p^{\prime}, p\right) \cup\{i\}$. Moreover, by Lemma 7 , $p_{i}^{\prime \prime}>0$. Hence,

$$
\sum_{i \in O\left(p^{\prime \prime}, p\right)} p_{i}^{\prime \prime} \omega_{i}+\beta W\left(p^{\prime \prime}\right)
$$




$$
\begin{gathered}
=\sum_{i \in O\left(p^{\prime \prime}, p\right)} p_{i}^{\prime \prime} \omega_{i}+\beta W\left(p^{\prime}\right) \\
>\sum_{i \in O\left(p^{\prime}, p\right)} p_{i}^{\prime} \omega_{i}+\beta W\left(p^{\prime}\right)=W(p)
\end{gathered}
$$

This contradicts the assumption that $p^{\prime} \in W^{a}(p)$.

\section{A.2.2 Incomplete RCs sets}

Proof of Proposition 6: The proof is similar to the proof of Proposition 4 and is therefore omitted. 